\title{
Do pandemic COVID 19 and business cycle influence the Indonesia composite index?
}

\author{
Chenny Seftarita ${ }^{1 *}$, Ferayanti $^{1}$, Fitriyani ${ }^{1}$, and Asri Diana ${ }^{1}$ \\ ${ }^{1}$ Development Economics Department, Universitas Syiah Kuala, Aceh, 23111, Indonesia.
}

\begin{abstract}
The impact of the Covid 19 pandemic on the Indonesian economy was worse than the impact of the global financial crisis in 2008. We can see the business cycle from the contraction of economic growth, volatility of the exchange rate, and inflation. The shocks to these business cycles could create systemic risks and influence financial system stability. Financial system stability is more sensitive to shocks from changes in one of the macroprudential indicators, namely the Indonesia Composite Index (ICI). This study will examine the effect of the Covid 19 pandemic and the business cycle on ICI. This research was conducted in Indonesia using quarterly secondary data from 2008-2021. The data was obtained from Bank Indonesia. The model used is the Auto Regressive Distributed Lag (ARDL) model. The purpose of using this model is to see the long-term and short-term relationships between the variables studied. The results show that the Covid 19 pandemic and business cycle variables such as; economic growth, exchange rate, and inflation have a relationship on the ICI both in the short and long term. The decline in economic growth during a crisis is difficult to avoid. However, the government must continue to accelerate the economic growth so it does not decline sharply during the crisis. Monetary authorities must also maintain exchange rate stability and inflation so it does not fluctuate unsteadily.
\end{abstract}

\section{Introduction}

Economic shock is characterized by a significant decline in economic growth. The indicators of economic shocks can be seen from fluctuations in economic growth [1]. Economic fluctuations will usually be followed by inflation and unemployment as a result of the cycle [2]. In the Indonesian case, the economic recession in 2020 is because of the Covid-19 pandemic. It caused a deep contraction shown by negative growth in the second and third quarters of 2020. This can be seen in Figure 1, where economic growth was recorded at $-5.32 \%$ in the second quarter and $-3.49 \%$ in the third quarter. This was the lowest recorded compared to pre-pandemic crises such as the 2008/2009 global crisis and the 2015 European crisis. During these two periods, economic growth is declined but continued to grow positively.

In 2020, the Indonesian economy experienced a sharp contraction due to the COVID-19 pandemic. This pandemic was firstly discovered in China [3] COVID19 and caused a severe acute respiratory illness that not only spreads fast around the world but also causes a lot of fatalities. It was confirmed to have spread to Indonesia in March 2020. The enormous number of deaths and sicknesses caused by the pandemic has caused extraordinary shocks to public health and the global economy. Stock markets, global supply

\footnotetext{
* Corresponding author: chenny@unsyiah.ac.id
}

networks, labor markets, and consumer behavior have all been impacted negatively by the pandemic.

Economic recession shown by negative growth did not only affect Indonesia but also became a threat to the global economy. The Covid 19 pandemic has infected approximately 50.27 million people in the world and nearly 1.26 million people died [4]. The pandemic is expected to cause the world economy to grow negatively related to mass movements (social and physical distancing), such as the results of studies by $[5,6]$. Even in developed countries such as the United States and the Euro Area, the predicted crisis due to this pandemic is greater than the 2008/2009 Global crisis and almost equal to the Great Depression period of 1930 [7].

Other indicators of the economic shock are fluctuations in inflation and the rupiah exchange rate. Figure 2 shows the growth of inflation as a variable that is strongly influenced by the economic cycle. The decline in economic performance due to economic shocks has complex impacts, such as; declining household consumption and declining business performance. Weakening purchasing power causes deflation. This condition is shown, Inflation has fallen and deflation occurred. Moreover, in the financial sector, capital outflows due to the shock caused the rupiah to depreciate. Despite being shaken by the pandemic, the rupiah exchange rate against the dollar in the second quarter became weakened to Rp16,310/USD. 
This depreciation was higher than the 1997/1998 monetary crisis period.

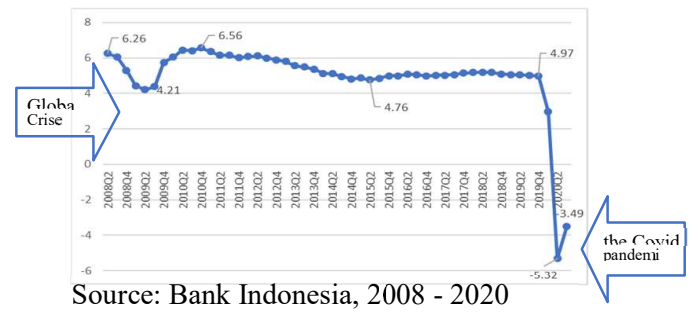

Fig. 1. Economic Growth Before and After the Covid 19 Pandemic.

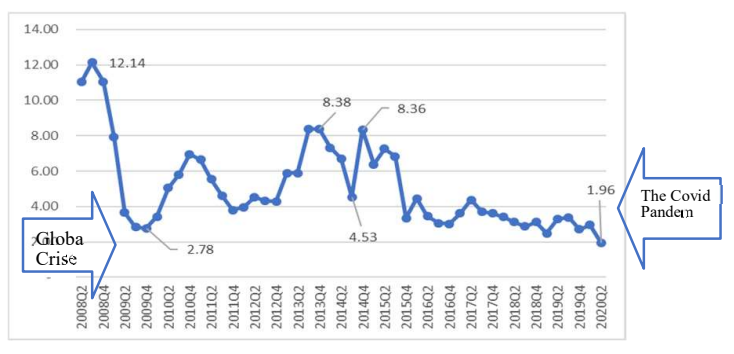

Source: Bank Indonesia, 2008-2020

Fig. 2. Inflation Before and After the Covid 19 Pandemic.

Furthermore, economic shocks have a major impact on Financial System Stability. The existence of a potential system makes the financial system vulnerable and leads to a deeper crisis. The instability of financial system causes several things; first, the monetary policy transmission mechanism becomes ineffective, the intermediation function is hampered, public distrust of financial institutions, and high-cost restructuring [8].

The financial system is divided into two, namely; financial market or capital market, financial intermediary institutions such as banking [9]. There are several steps in the macroprudential policy, including; financial institutions, macroeconomic conditions, financial markets and infrastructure, corporations, and households [10]. Several macroprudential variables are used as financial system measurements, one of which is the Composite Stock Price Index (ICI). A stable capital market reflects good economic conditions, on the other hand, unfavourable and unstable economic conditions will cause capital market performance to be vulnerable to decline. This can be seen from the decline in the ICI.

Economic cycle fluctuations will greatly affect macroprudential indicators, including the Jakarta Composite Index. Several studies analyse how the impact of economic shocks on the stock market. [11,12], analysed the effect of shock on the economic cycle in the stock market using the Vector Autoregressive (VAR) approach. The findings found that economic turmoil is a condition of uncertainty and affects the decline in stock market performance. [13] examines the distribution of the economic crisis in global finance and the real sector in several regions, such as Asia and Europe. A larger regional shock to the real sector can be seen from the collapse of financial markets due to the crisis. [14] looks at the synchronization between business cycles in the United States and the rest of the world. The crisis in America triggered a global crisis and financial crises in various countries. The related equity markets across countries experienced a sharp decline during the crisis period.

Research on the effect of economic shocks and their comparison with the period before and after the occurrence of Covid 19 using dummy variables is relatively new in this study. Financial System Stability is also newly being studied in depth by monetary authorities. Based on this background, the researcher will examine the effect of the business cycle and the shocks of the Covid 19 pandemic on the Composite Stock Price Index in the long and short term.

\section{Research methodology}

This study analyses the effect of the economic cycle and the Covid 19 pandemic on the Indonesian Composite Stock Price Index as one of the macroprudential variables in Indonesia. The data used in this study is secondary data sourced from Bank Indonesia, Federal Reserve Economic Data (FRED), and the Financial Services Authority (OJK). The data used is quarterly data from 2008-2020. This study uses a dynamic model and analyses the long-term and short-term relationships between variables. This research uses ARDL (Autoregressive Distributed Lag) model. The following equation will be regressed with the ARDL model:

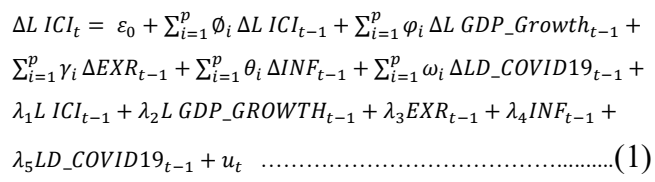

The dependent variable used is one of the macroprudential indicators, namely ICI or the Composite Stock Price Index as the dependent variable. Independent variables as proxies for economic shocks include economic growth, the exchange rate of EXR or Rupiah against the dollar, INF or inflation, and D_Covid19 or Dummy before and before the Covid 19 pandemic. $\varnothing, \varphi, \gamma, \theta, \omega$ shows a short-term relationship, $\lambda_{1}, \lambda_{2} \ldots \lambda_{5}$ shows long term relationship, $\mathrm{t}$ is time, $\mathrm{ut}$ is error term. All variables are in log form, except those in the form of proportions whose purpose is to see the sensitivity of the dependent variable to the independent variable (economic shocks). In the ARDL model, several tests were carried out, including (1) Stationarity Test, (2) Optimum Lag Test, and (3) Model Stability Test (classical assumption test, such as autocorrelation, multicollinearity, and heteroscedasticity). 


\section{Results and discussion}

Before entering the regression stage, a unit root test is firstly performed on each variable used. Based on the test results with the Phillips-Perron test statistic, all variables are not stationary at the level. The test is then continued at the first difference and the results show that all variables are stationary at the first difference. After the stability test, the next step is the optimal lag test using Akaike Information Criterion (AIC)). Based on these tests, the optimal lag used in this study is the ARDL lag $(1,1,1,2,3)$. This lag will be used in the estimation of ARDL in this study.

Tabel 1. Unit root test results unit root test results.

\begin{tabular}{|c|c|c|}
\hline Variables & At Level & $\begin{array}{c}\text { At First } \\
\text { Difference }\end{array}$ \\
\hline ICI & Not Stationary & Stationary \\
\hline GDP_GROWTH & Not Stationary & Stationary \\
\hline INF & Not Stationary & Stationary \\
\hline EXR & Not Stationary & Stationary \\
\hline D_COVID19 & Not Stationary & Stationary \\
\hline
\end{tabular}

The next stage is regression using the ARDL model, followed by model testing and classical assumption tests, namely autocorrelation, multicollinearity and heteroscedasticity tests. Table 2 shows the Autocorrelation Test Results. Based on the test results, the estimation model is free from autocorrelation problems, as seen from the insignificant probability value at the $5 \%$ confidence level.

Table 2. Autocorrelation test.

Q-statistic probabilities adjusted for 1 dynamic regressor

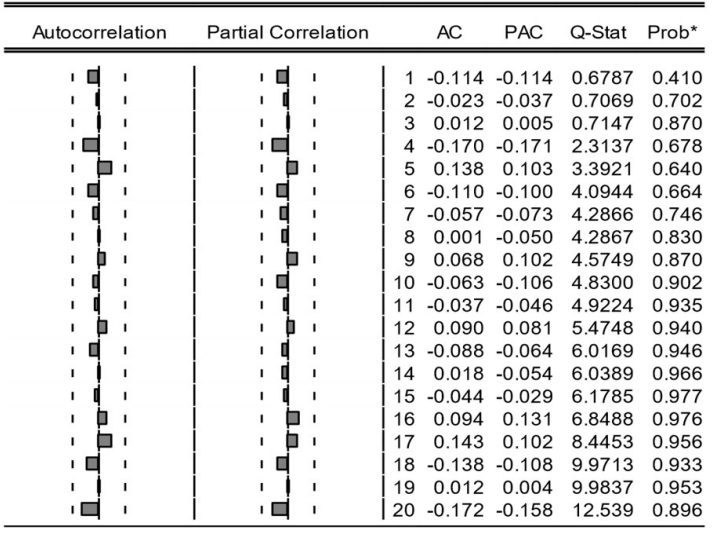

The test was carried out with a multicollinearity test and heteroscedasticity test. The multicollinearity test uses the Breusch-Godfrey Serial Correlation LM Test method. The result shows that this model is free from multicollinearity problems, where the probability of Chi-Square is not significant. Likewise, the heteroscedasticity test using Breusch-Pagan-Godfrey, the model also rejects the heteroscedasticity problems as seen from the insignificant Chi Square probability value. The last stage is testing the value of the model category

as shown in Figure 3. Based on the results of the CUSUM and CUSUM OF SQUARE tests, it can be seen that the most stable model (as seen from Cusum and Cusum from the boxes in a significant area). After going through all the testing stages, the ARDL model can be used for interpretation.
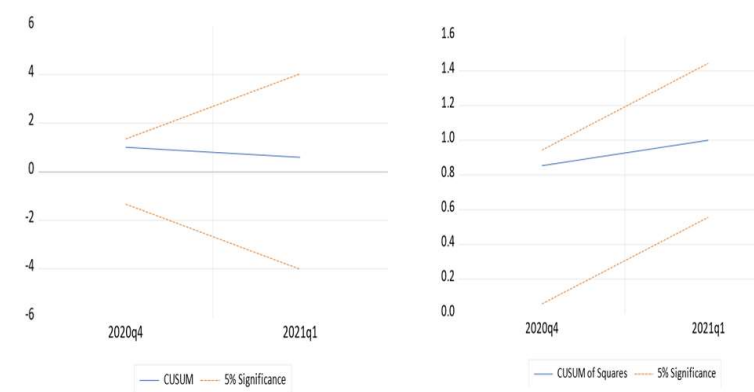

Fig. 3. Model stability test.

Table 3 is the result of short-term estimation. In general, the economic cycle and the COVID-19 pandemic significantly affect the Jakarta Composite Index (JCI) in the short term. This can be seen from the value of CointEq (-1) known as the Error Correction Term (ECT) which is negative and significant, and $<1$. Partially, almost all variables are significant at $5 \%$ alpha. The Covid 19 pandemic in the $\mathrm{t}-1$ and $\mathrm{t}-2$ periods greatly affected the decline in ICI. The pandemic caused stress for investors and demand for portfolio investments such as stocks and bonds to decline. These conditions cause a general decline in stock prices. The economic cycle variables, namely economic growth, exchange rates, and inflation also show a significant effect in the short term. The decline in economic growth caused the ICI to be sharply corrected in period $t$ (current year). The weakening of the exchange rate in period $t$ also has a negative effect on ICI. The inflation variable previously showed a positive effect on the ICI. This condition is probably caused by targeting inflation which ensure the inflation to be under control and thus, its percentage is still low. Even a short-term increase raises positive expectations among investors so that public demand or purchasing power is still quite high.

Table 3. ARDL Error Correction Regression Case 2: Restricted Constant and No Trend.

\begin{tabular}{ccccc}
\hline \hline & & & & \\
Variable & Coefficient & Std. Error & t-Statistic & Prob. \\
\hline \hline & & & & \\
D(GDP_GROWTH) & -388.5826 & 107.8668 & -3.602431 & 0.0009 \\
D(EXR) & -0.447629 & 0.067427 & -6.638738 & 0.0000 \\
D(INF) & 2.416004 & 24.17954 & 0.099919 & 0.9210 \\
D(INF(-1)) & 84.99678 & 27.19477 & 3.125483 & 0.0035 \\
D(D_COVID19) & -148.9885 & 219.6205 & -0.678391 & 0.5019 \\
D(D_COVID19(-1)) & -1502.042 & 341.1534 & -4.402833 & 0.0001 \\
D(D_COVID19(-2)) -4186.599 & 999.9504 & -4.186807 & 0.0002 \\
CointEq(-1)* & -0.083294 & 0.014031 & -5.936448 & 0.0000 \\
\hline \hline R-Squared : 77,45 \% & & & \\
Adj R_Squared: $73,59 \%$ & & & \\
DW Stat: 2.223 & & & &
\end{tabular}


Table 4. Long-term estimation with bound tests.

\begin{tabular}{|l|l|l|c|l|}
\hline Test Statistic & Value & Signif. & $\mathrm{I}(0)$ & $\mathrm{I}(1)$ \\
\hline F Statistic & 5.16 & $10 \%$ & 2.2 & 3.09 \\
\hline K & 4 & $5 \%$ & 2.56 & 3.49 \\
\hline & & $2.5 \%$ & 2.88 & 3.87 \\
\hline & & $1 \%$ & 3.29 & 4.37 \\
\hline
\end{tabular}

$\mathrm{EC}=\mathrm{ICI}-(-1093,8 *$ GDP GROWTH $-0,089 * \mathrm{EXR}-$ $538.5 *$ INF $-209,2 *$ D_COVID19 + 16005.1

Based on the results of the long-term test using the Bound Test in Table 4, it can be seen that all independent variables have a long-term relationship with the dependent variable. This can be seen from the values of $\mathrm{I}(0)$ and $\mathrm{I}(1)$ which are less than the value of F Statistics, at a confidence level of 1-10 percent. This means that in the long term, the economic cycle and the Covid-19 pandemic will greatly affect ICI. Partially, in the long term, all variables do not show a significant effect on ICI. This can be seen in equation 2 above. The relationship between the variables above is in line with the results of research by Tsai (2017) and Caldara et al (2016). Therefore, the slowdown in economic growth in the event of an economic shock will have a negative impact on the composite stock price index, especially in the short term.

\section{Conclusion}

The decline in economic growth during a crisis is difficult to avoid. However, the government must continue to accelerate the economic growth so it does not decline sharply during the crisis. Monetary authorities must also maintain exchange rate stability and inflation to not fluctuate. The weakening of the exchange rate and rising inflation will further exacerbate the crisis. Regarding the Covid 19 pandemic, the government must try harder to reduce the spread of the coronavirus in various regions in Indonesia, considering that the root cause of the economic downturn that occurred in the 2020-2021 period is the Covid 19 pandemic. In addition, it is essential to weaken the profound impact of the pandemic on the financial system and economy.

\section{References}

1. R. Dornbusch and S. Fischer, Macroeconomics, Eleventh E (McGraw-Hill, 1994, 2011)

2. O. Blanchard, A. Amighini, and F. Giavazzi, Macroeconomics: A European Perspective (Pearson Education Limited, England, 2010)

3. Kementerian Kesehatan, Kementeri. Kesehat. RI 2, 1 (2020)

4. Kementerian Kesehatan, (2021)

5. N. Fernandes, IESE Bus. Sch. Work. Pap. No. WP-124, 0 (2020)

6. Centre for Economic Policy Research, Economic in the Time of Covid-19 (CEPR Press, London, 2020)

7. R. Barichello, Can. J. Agric. Econ. 68, 219 (2020)

8. Bank Indonesia, Macroprudential Policy (2018)

9. F. S. Mishkin, The Economics of Money, Banking, and Financial Markets, Tenth Edit (Pearson, 2013)

10. G. J. Schinasi, Understanding Financial Stability: Towards a Practical Framework (2007)

11. D. Caldara, C. Fuentes-Albero, S. Gilchrist, and E. Zakrajšek, Eur. Econ. Rev. 88, 185 (2016)

12. K. Sugimoto, T. Matsuki, and Y. Yoshida, Emerg. Mark. Rev. 21, 201 (2014)

13. D. Kenourgios and D. Dimitriou, Econ. Model. 44, 283 (2015)

14. J. H. Pyun and J. An, J. Int. Money Financ. 67, 172 (2016) 